\title{
Environmental impact of intensive farming in sloping areas
}

\author{
Giovanni Bosco ${ }^{1 *}$, and Lucia Simeoni ${ }^{2}$ \\ ${ }^{1}$ DICEAA, University of L'Aquila, Monteluco di Roio, 67040 L'Aquila, Italy \\ ${ }^{2}$ DICAM, University of Trento, Via Mesiano 77, 38050 Trento, Italy
}

\begin{abstract}
The increased demand for food causes intensive farming with high yield production and large water consumption to extend significantly. Depending on soil properties, seasonal rainfall, surface drainage and water resources, hence the consumption-infiltration balance, the ground water table might be raised or depleted; soils could be saturated or remain partly saturated with negative pore pressures. As a result sloping grounds may become prone to shallow slides, as mudflows, or deep seated movements, involving large volumes of soil, especially after rupture of major watering lines or after long uncontrolled irrigations. Within this framework the paper investigates the possible effects of replacing grassland with intensive apple farming on the stability conditions of slopes. Apples require frequent watering, especially during spring and summer to meet qualitative and quantitative productive standards. Also, sprinkler irrigation is often used to protect against hail. From the precipitation, irrigation, runoff, evaporation and plant transpiration balance, the evolution of the pore water pressure distribution within an average year is calculated. Then the modified shear strength of the unsaturated-saturated soils is determined and the factor of safety against sliding is calculated.
\end{abstract}

\section{Introduction}

Knowledge of the pore water pressures is fundamental in assessing the stability and safety against failure of geotechnical structures, such as natural slopes, artificial cuts, buried structures, retaining walls, foundations. In the vicinity of the ground surface, and at greater depths in fine soils, the unsaturated state is generally prevailing, and pore pressures shift into the negative range. In such cases the interplay between pore water, pore air pressure, interparticle stresses, governs the size and distribution of the pores, the volume of voids, the mechanisms of water retention, the permeability, the deformability and the shear strength of the particle assembly.

Under intensive farming conditions, positive and negative pore pressures will vary with depth depending on type of vegetation and growing practices, irrigation procedures, local climate and resulting evapotranspiration, available water sources. Thus, initially stable slopes may become prone to sliding after introducing new species that require extensive watering, as a result of increasing the pore pressures and rising the water table $[1,2,3]$; in general in

\footnotetext{
*Corresponding author: giovanni.bosco@univaq.it
} 
fact the benefits from the tensile resistance of the rooting apparatus and the associated confining actions are quite limited and apply to the vegetated soil layers only.

This paper aims at understanding how the stability conditions were modified after grasslands were replaced with intensive apple farming. The study is applied to the Val di Non area, in northern Italy, where thousands of hectares were replanted with irrigated high yield apple trees; these require extensive watering, especially in hot summers, to meet qualitative and quantitative production standards.

For purpose of the investigation, a soil-atmosphere interaction analysis is performed for three cases: 1) grass, not irrigated, 2) newly planted apples (1 year old), 3) fully productive and mature trees ( 5 years old). In addition sprinkler and drip irrigation are considered.

For each of these cases, numerical analyses are performed to trace the variation of the pore water pressure distribution with depth and with time throughout an average one-year time interval, to include the four seasons history of rain and temperature at ground surface. The water balance is reproduced for a unit column of cultivated soil, considering rainfall and irrigation, with relative runoff losses, and water consumption due to evapotranspiration. The effects of the irrigation technique are accounted for by varying the wetted surface and the root apparatus, distributed or concentrated in narrow aisles between dryer corridors.

Once the evolution of the pore water pressures distribution is obtained, the variation of the shear strength and of the factor of safety for different sliding mechanisms can be calculated throughout the one-year average weather history.

\section{Site data}

The study area is comprised in the Val di Non valley (Norhern Italy), on the West side of the Adige River, North-West of Trento, and resembles an undulating wide plateau, at average elevations of 500-700 m m.s.l.. The valley has been shaped by the actions of advancing and retreating glaciers and more recently by the Noce river; they originated the actual subsoil conditions.

To facilitate the use of machinery, the cultivated surfaces are kept at average slopes of $16^{\circ}$, with trees grown along parallel rows 3.2-3.5 m apart, at distances of 0.8-0.9 m. Low retaining walls are used to separate properties and maintain the required slopes.

\subsection{Subsoil conditions}

Throughout the valley a thick moraine of glacier and river origin is typically encountered over a marly-limestone bedrock. This moraine is predominantly composed by mixtures of silt and sand with rock fragments, ranging in size from gravel to cobbles to large blocks. The superficial layer is generally finer due to modification caused by agricultural activities.

Data on soil characteristics come from previous tests on numerous samples aimed at classifying the superficial layers for agricultural purposes. Samples were retrieved at shallow depths, less than about $2 \mathrm{~m}$ below surface.

\subsubsection{Grain size distribution}

Available data on the grain size distribution are relatively limited, since only six classes of diameters were determined; clay $(<2 \mu \mathrm{m})$, fine silt $(2-4 \mu \mathrm{m})$, large silt $(4-60 \mu \mathrm{m})$, fine sand $(0.06-0.5 \mathrm{~mm})$, large sand $(0.5-2 \mathrm{~mm})$, gravel $(>2 \mathrm{~mm})$. Largest particles remain below 80 $\mathrm{mm}$; no data are available for diameters smaller than $1 \mu \mathrm{m}$.

Once the data were plotted together, it was recognized that samples had essentially a similar soil composition, no matter the depth they had been retrieved, except for a general 
increase in silt content approaching ground surface. At the same time a general increase in sand content for depths greater than $1.0 \mathrm{~m}$ was noted.

Therefore, a model curve was adopted for purpose of this study, assuming a uniform soil layer with $30 \%$ clay content $(<2 \mu \mathrm{m}), 50 \%$ silt content $(2-50 \mu \mathrm{m}), 20 \%$ sand content $(>50$ $\mu \mathrm{m})$, void ratio $\mathrm{e}=0.7$ and specific gravity $\mathrm{Gs}=2.5$, given the presence of organic matter, especially at shallow depths.

\subsubsection{Permeability}

Because neither laboratory nor field tests had been performed to measure soil permeability, this property was estimated using literature correlations.

Under saturated conditions an hydraulic conductivity $k s$ of $9.6 \cdot 10^{-8} \mathrm{~m} / \mathrm{s}$ was assumed. It was calculated by averaging the values obtained with two relationships:

1) the Kozeny-Carman [4] relationship:

$$
\log \left(k_{s}\right)=0,5+\log \left(\frac{e^{3}}{\left(G_{s}{ }^{2} S_{s}{ }^{2} \cdot(1+e)\right)}\right)\left[\frac{m}{s}\right]
$$

in which the specific surface $\mathrm{Ss}\left(\mathrm{m}^{2} / \mathrm{kg}\right)$ is determined with the relationship:

$$
S_{s}=\frac{6}{G_{S} \rho_{w}} \cdot \sum_{i=1}^{n} \frac{P_{D_{i}}-P_{d_{i}}}{d_{i}}\left[\frac{m^{2}}{k g}\right]
$$

with $\rho_{\mathrm{w}}$ the mass density of water, $\mathrm{P}_{\mathrm{Di}}$ and $\mathrm{P}_{\mathrm{di}}$ the percentage of dry mass of soil between successive sieves with nominal diameters $\mathrm{D}$ and $\mathrm{d}$ respectively;

2) and the Chapuis [5] relationship:

$$
k_{s}=2,4622 \cdot\left(d_{10}^{2} \cdot \frac{e^{3}}{(1+e)}\right)^{0,7825}\left[\frac{\mathrm{cm}}{\mathrm{s}}\right]
$$

The relationship between total suction $\left(\mathrm{s}_{\mathrm{t}}\right)$ and volumetric water content $(\theta)$ has been defined according to Van Genuchten [6], with parameters by Vereecken [7]:

$$
\theta=\theta_{r}+\frac{\left(\theta_{s}-\theta_{r}\right)}{\left[1+\left(a s_{t}\right)^{n}\right]^{m}}
$$

Here $\left(\mathrm{s}_{\mathrm{t}}\right)$ is expressed in centimetres of head and $\mathrm{m}$ is assumed equal to 1 . Values of the saturated and residual volumetric water contents and of the other parameters are obtained as follows: $\theta_{\mathrm{s}}=0.81-0.283\left(\rho_{\mathrm{d}}\right)+0.001(\mathrm{C})=0.407, \theta_{\mathrm{r}}=0.015+0.005(\mathrm{C})+0.014(\mathrm{CO})=$ $0.165, \alpha=\operatorname{Exp}\left[-2.486+0.025(\mathrm{~S})-0.351(\mathrm{CO})-2.617\left(\rho_{\mathrm{d}}\right)-0.023(\mathrm{C})\right]=1.2610^{-3}[1 / \mathrm{cm}]$, $\mathrm{n}=\operatorname{Exp}\left[0.053-0.009(\mathrm{~S})-0.013(\mathrm{C})+0.00015(\mathrm{~S})^{2}\right]=0.633$, with the following data:, dry mass density $\rho_{d}=1.53$, clay content $C=30 \%$, sand content $S=20 \%$ (silt $=50 \%$ ), carbonic fraction $\mathrm{CO}=0$.

For unsaturated conditions the hydraulic conductivity function has been defined in accordance to Gardner [8] and Vereecken [9], in terms of relative hydraulic conductivity $\left(\mathrm{k}_{\mathrm{r}}\right)$, ratio between the conductivity under unsaturated $(\mathrm{k})$ and saturated $\left(\mathrm{k}_{\mathrm{s}}\right)$ conditions:

$$
k_{r}=1 /\left[1+\left(b s_{t}\right)^{\lambda}\right]
$$

To determine $\left(\mathrm{k}_{\mathrm{r}}\right)$ the same sand, silt, and clay contents indicated before were adopted, with total suction $\left(\mathrm{s}_{\mathrm{t}}\right)$ in centimetres of head. Values of the parameters $\mathrm{b}$ and $\lambda$ have been determined from $b=\operatorname{Exp}\left[-2.64-0.019 \mathrm{~S}+0.05 \mathrm{C}+0.506 \ln \left(\mathrm{k}_{\mathrm{s}}\right)\right]=0.199(1 / \mathrm{cm})$ and from 
$\lambda=\operatorname{Exp}[1.186-0.194 \ln (\mathrm{C})-0.0489 \ln ($ silt $)]=1.398$.

The resulting permeability curve was arbitrarily shifted [10] to increase the unsaturated conductivity $(\mathrm{k})$ keeping the saturated one $\left(\mathrm{k}_{\mathrm{s}}\right)$ unchanged, to account for the reduction of clay and silt contents with depth and also because the porosity near the surface and in the rooted layer increases due to agricultural activities (plowing, uprooting, refurbishing).

\section{Water balance}

For the average climatic year, the soil-atmosphere interaction is modelled balancing the water flux, thus the time history of rainfall, irrigation with runoff losses, evapotranspiration.

Rainfall time history was obtained by averaging a twenty years long (1984-2004) set of data registered in a weather station (Cles) at the northernmost edge of the valley.

As in the recorded data set, average values of precipitation were grouped in ten days intervals. Highest and lowest precipitations are registered in October-November, with total rainfall of $40 \mathrm{~mm}$ in 10 days, and in March, with a cumulative $7 \mathrm{~mm}$ in 10 days.

Runoff losses were assumed at $20 \%$ of registered rainfall, based on local experience and past observations; the remaining net rainfall $(80 \%$ of the averaged total) is assumed to infiltrate. Because precipitations are averaged over a 10 days interval, peak intensities are smoothened out; thus runoff losses obtained by seepage analyses would be underestimated.

Following local practice, the volumes of water delivered with sprinklers is equivalent to a precipitation intensity of $1.97 \mathrm{~mm}$ per day, uniformly wetting the ground. Watering schedules are based on continuous irrigation over 2-3 hours per day; therefore the resulting intensity is rather high. Since irrigation is usually started when the soil appears dry, thus permeability can be quite low, runoff losses have been set to $40 \%$, as per local experience.

Drip irrigation minimizes runoff, since watering and soil wetting are limited to a small volume around the plant and its roots. Thus no runoff is assumed. Drip irrigation is equivalent to a rain intensity of $1.15 \mathrm{~mm}$ per day, less than net precipitation for sprinklers.

\subsection{Evapotranspiration}

The potential evapotranspiration has been calculated with the Penman-Montheit [11] expression as modified by Jarvis and McNaughton [12], regardless the type of vegetation:

$$
P E T=\frac{\Delta R_{n}+\eta \zeta \rho c_{p} D_{a} g_{a}}{\lambda\left[\Delta+\eta \gamma\left(\zeta+\frac{g_{a}}{g_{s}}\right)\right]}
$$

with $\mathrm{R}_{\mathrm{n}}$ net radiation, $\mathrm{g}_{\mathrm{a}}$ boundary layer conductance, $\mathrm{g}_{\mathrm{s}}$ "big leaf' stomatal conductance, $D_{a}$ ambient air vapour pressure deficit, $\gamma$ psychometric coefficient, $\rho$ air density, $c_{p}$ air specific heat at constant pressure, $\Delta$ slope of the saturation vapour pressure curve at air temperature, and $\lambda$ the latent heat of vaporization.

The factor $\eta$ represents the ratio between boundary layer conductance for water vapour and for sensible heat; its most probable value is 0.93 [13]. The factor $\zeta$ arises from the energy balance of the big leaves; $\zeta=1$ if the leaf has stomata on both sides and $\zeta=2$ if the stomata are in one side only.

The boundary layer conductance $\mathrm{g}_{\mathrm{a}}$ (in $\mathrm{m} / \mathrm{s}$ ) can only be estimated; for trees with leaves subjected to mutual interference the model proposed by Landsberg and Powell [14] is used:

$$
g_{a}=0.0172 p^{-0.56}\left(\frac{U}{D}\right)^{0.5}
$$


in which $\mathrm{p}$ is estimated as the ratio between the tree leaf area and its silhouette area $\mathrm{p}_{\mathrm{v}}$ projected onto a vertical plane [13], D is a characteristic leaf dimension ( $\mathrm{m})$, sometimes taken as the square root of the mean leaf area $(\mathrm{Al})$, and $\mathrm{U}$ the average wind speed $(\mathrm{m} / \mathrm{s})$ at the midcanopy heights.

In the case of grass it was assumed $\mathrm{Al}=2.88 \mathrm{~m}^{2}, \mathrm{p}_{\mathrm{v}}=0.1 \mathrm{~m}^{2}, \mathrm{D}=1.69 \mathrm{~m}$ (unit surface); these values were considered constant throughout the average one year time interval.

Instead for apple trees it must be considered that $\mathrm{Al}, \mathrm{p}_{\mathrm{v}}$ and $\mathrm{D}$ vary during the year and with time, as plants grow bigger and height increases from about $1.8 \mathrm{~m}$ for newly planted trees (one year old) to $3.2 \mathrm{~m}$ for mature and fully productive trees (five years and above).

The actual evapotranspiration AET has been estimated according to Wilson et al. [15]

$$
\frac{A E T}{P E T}=\frac{\left[\exp \left(\frac{W_{v} \cdot \Psi g}{R T}\right)-h_{a}\right]}{1-h_{a}}
$$

with $\mathrm{W}_{\mathrm{v}}$ the molecular weight of water, $0.018 \mathrm{~kg} / \mathrm{mol}$, g gravity acceleration $\left(\mathrm{m} / \mathrm{s}^{2}\right), \Psi$ the total suction in the liquid water phase expressed as equivalent matric suction and as negative value $(\mathrm{m}), \mathrm{R}$ the universal gas constant $[8.314 \mathrm{Joule} /(\mathrm{mol} \mathrm{K})]$, T absolute temperature $(\mathrm{K})$, $\mathrm{h}_{\mathrm{a}}$ the relative humidity of the air above the evaporating soil.

Using the values $\mathrm{T}=282.45^{\circ} \mathrm{K}$ and $\mathrm{h}_{\mathrm{a}}=69.9 \%$ obtained averaging the data recorded in the weather station the actual evapotranspiration AET resulted equal to the potential PET evapotranspiration PET for suctions less than $500 \mathrm{kPa}$.

\subsection{Geometry of wetted areas and of root apparatuses}

To obtain a reasonable estimate of the evapotranspiration for the different species, the irrigation techniques, the age of the trees and their spacing have been considered.

It has been observed that sprinklers make a uniformly wetted surface pushing roots to spread out all around; in time they form an almost continuous apparatus. Hence in this case net precipitation, watering, evapotranspiration were applied uniformly at ground surface.

Instead, for drip irrigation three schemes have been considered [10]. The first one (called Geom.1) assumes uniform evapotranspiration, and differs from sprinklers for the reduced volumes of water. The second one (Geom.2A) and the third one (Geom.2B) assume concentrated root apparatus and reduced wetted areas, limited to $0.8 \mathrm{~m}$ on each side of the row of trees. Consequently, evapotranspiration is not uniform along the aisle, but it concentrates beside the trees. Then, two values of evapotranspiration have been adopted in these cases: the $70 \%$ of the epotranspiration due to the apple trees is set in the vicinity of the trees, for a distance of $0.8 \mathrm{~m}$ on each side of the row of plants; in the remaining portion of the aisle $(0.8 \mathrm{~m})$ the evapotranspiration of grass is applied in Geom.2A or the remaining $30 \%$ due to the apple trees in Geom.2B.

Figures 1-2 show calculated values of cumulative net rainfall, irrigation, and PET for grass and apple trees and for different watering systems. It is worth noting that net rainfall is similar to evapotranspiration for lawn and for newly planted trees (one year old), despite these are irrigated to help them grow onto the productive stage. Instead, PET of mature trees (five years old) is quite greater than net rainfall, despite they get essentially the same amount of water than the younger trees. 


\section{Numerical model for water balance analyses}

The flow of water through the ground surface and the resulting distribution of pore water pressures with depth have been modelled with the commercial code SEEP/W by Geostudio.

For the case of sprinkler irrigation (Geom.1) a 1D soil column with a cross section of unit area is considered. In the case of drip irrigation (Geom.2A, Geom.2B) a 2D soil slab is assumed (infinite length). Due to symmetry this slab is $1.6 \mathrm{~m}$ wide, since trees are planted along rows $3.2 \mathrm{~m}$ apart. In both cases the soil deposit extends to a maximum depth of $6 \mathrm{~m}$.

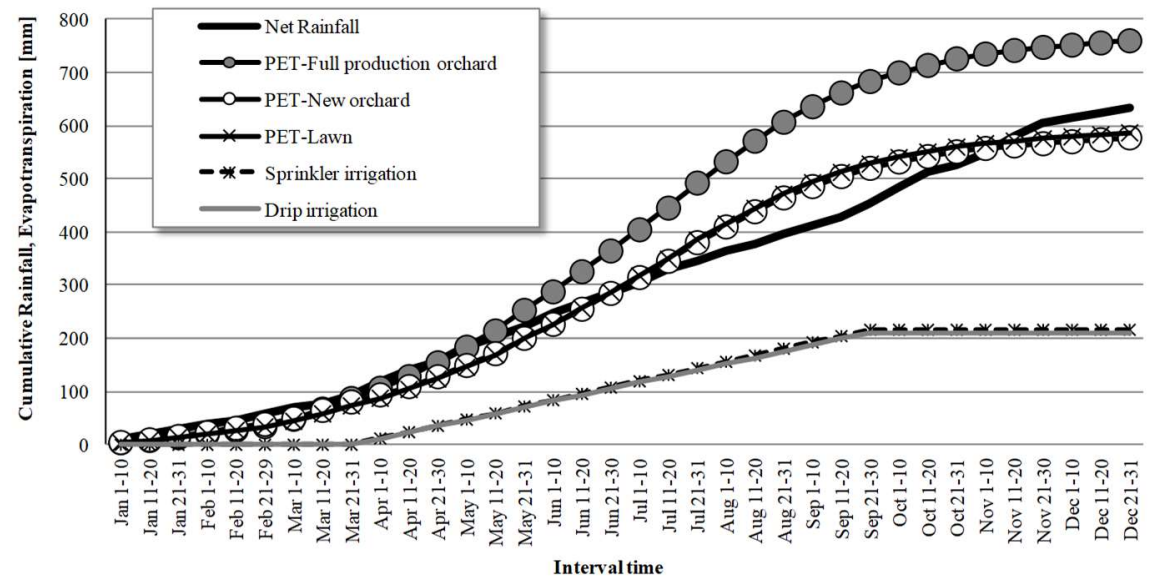

Fig. 1. Cumulative Net Rainfall, PET for Lawn, New and Full production Orchard, Sprinkler and Drip Irrigation.

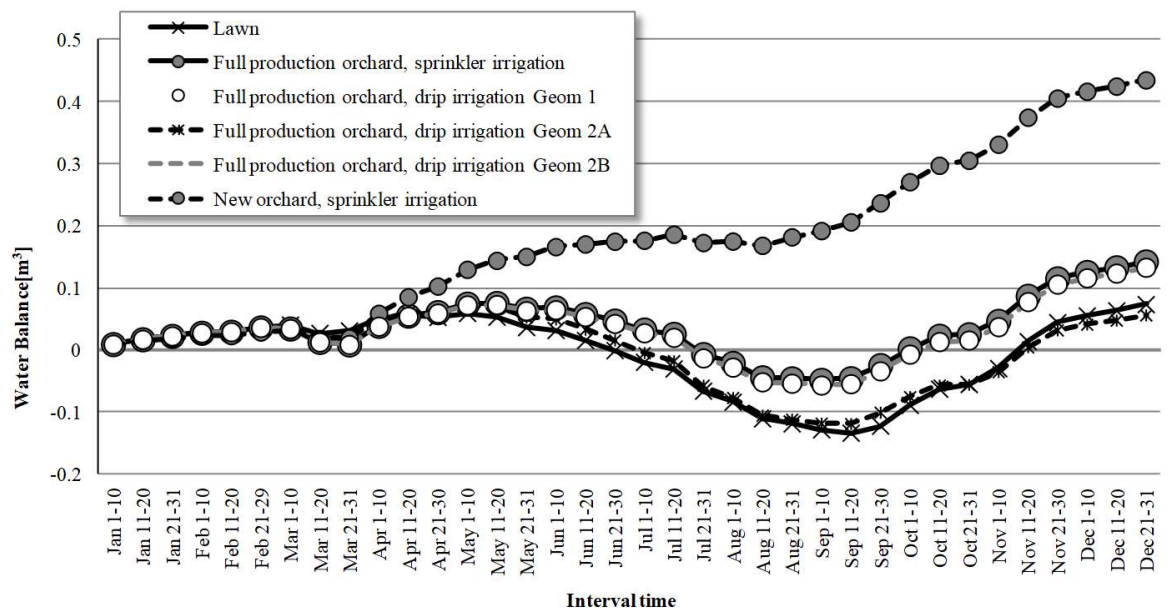

Fig. 2. Water balance throughout the one year interval for different species and irrigation procedures.

Boundary conditions include unit flux at ground surface and impermeable contours (no flux) below. Initial groundwater is set at depths of $5 \mathrm{~m}$ and $6 \mathrm{~m}$ for Geom. 1 and at depth of 6 $\mathrm{m}$ for the other two cases (Geom.2A, Geom.2B).

The unit flux is calculated from the algebraic sum of net rainfall, irrigation and AET; AET is equal to PET since soil suction never exceeds $500 \mathrm{kPa}$. The unit flux at ground surface changes every 10 days, following the average rainfall history. It is the same as applying a step function of constant flux within each time interval of 10 days. 
Calculations start from an initial steady state condition with hydrostatic water pressures; these are null at the water table ( 5 or $6 \mathrm{~m}$ below surface) and reach maximum negative value at ground surface $(-5(9.81) \mathrm{kPa}$ or $-6(9.81) \mathrm{kPa})$.

Figure 3 shows the effects of irrigation procedures and type of vegetation on the pore pressures at a depth of $1 \mathrm{~m}$. Figure 4 shows the amount of groundwater rising $\left(\mathrm{H}_{\mathrm{w}}\right)$ above reference depth of $6 \mathrm{~m}(\mathrm{H})$ expressed by the ratio $\mathrm{m}$ of the two values, $\mathrm{m}=\left(\mathrm{H}_{\mathrm{w}}\right) /(\mathrm{H})$.

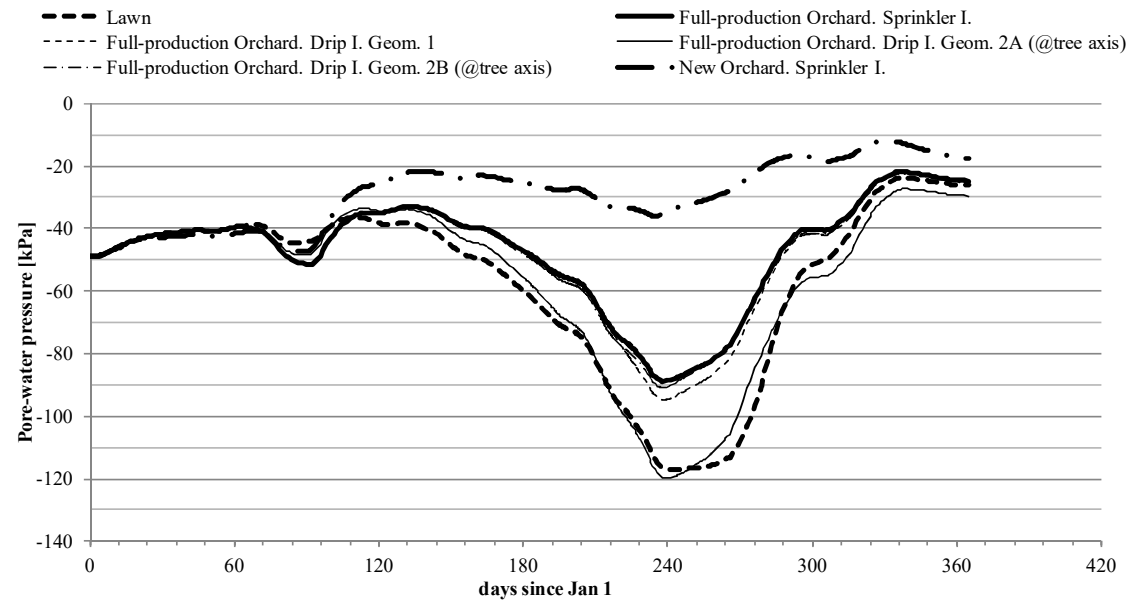

Fig. 3. Pore pressures at depth of $1 \mathrm{~m}$ for different vegetation and irrigation procedures; one year time interval; initial ground water table at depth of $6 \mathrm{~m}$ below ground surface.

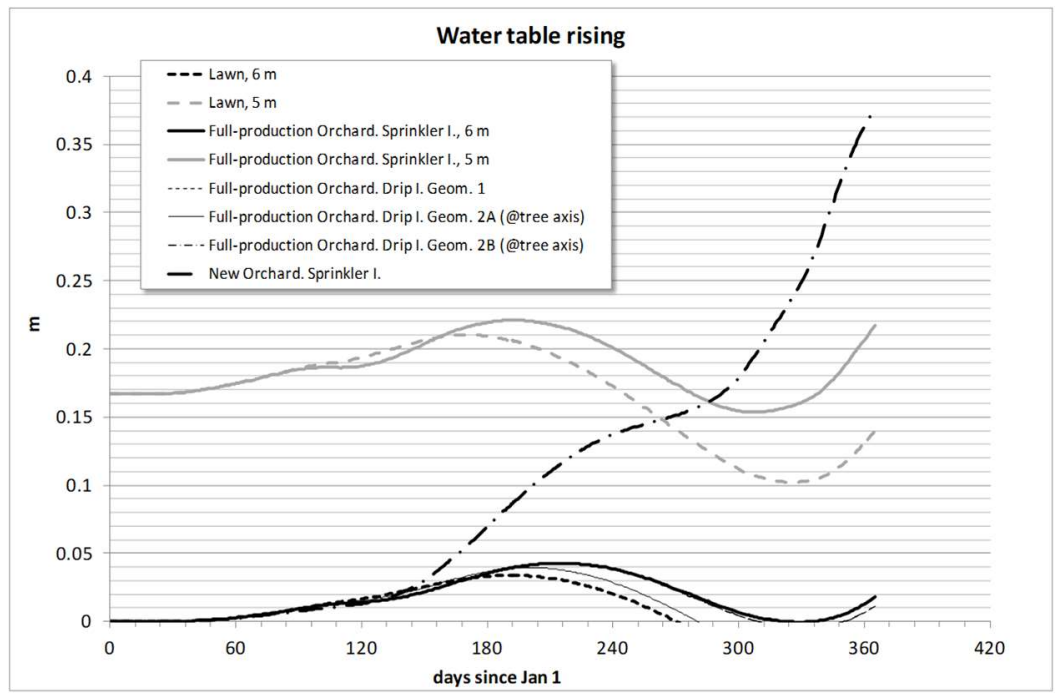

Fig. 4. Groundwater changes for different vegetation and irrigation procedures; one year time interval; initial ground water table at depths of $5 \mathrm{~m}$ and $6 \mathrm{~m}$ below ground surface.

\section{Slope stability analyses}

To evaluate the effects of the varying pore water pressure distribution with time to slope stability, the safety against sliding has been calculated considering the simple geometry of an infinite slope and purely translational failure along planar surfaces parallel to the ground 
surface (Figure 5).

The shear strength on the failure surface is obtained using the Mohr-Coulomb equation by using the relationship proposed by Bishop [16] with values of the $\chi$ parameter from Khalili and Khabbaz [17] to include the shear strength increase induced by suction :

$$
\begin{gathered}
\tau_{f}=c^{\prime}+\sigma_{n}^{\prime} \cdot \tan \varphi^{\prime} \quad \text { with } \quad \sigma_{n}^{\prime}=\left(\sigma_{n}-u_{a}\right)+\chi \cdot\left(u_{a}-u_{w}\right) \\
\chi=1 \text { if }\left(u_{a}-u_{w}\right) \leq\left(u_{a}-u_{w}\right)_{b} a \\
\chi=\left[\frac{\left(u_{a}-u_{w}\right) /}{\left(u_{a}-u_{w}\right)_{b}}\right]^{-0.55} \text { if }\left(u_{a}-u_{w}\right)>\left(u_{a}-u_{w}\right)_{b}
\end{gathered}
$$

Given the relatively limited amount of fines an air entry value $\left(u_{a}-u_{w}\right)_{b}=1 \mathrm{kPa}$ was assumed. At depths of $1.0 \mathrm{~m}, 1.5 \mathrm{~m}$ and $2.0 \mathrm{~m}$, the soil suction is always greater than $1.0 \mathrm{kPa}$, therefore stability analyses were performed using the following equations:

$$
\begin{gathered}
\chi=\left(u_{a}-u_{w}\right)^{-0.55} \quad \tau_{f}=\left[\left(\sigma_{n}-u_{a}\right)+\left(u_{a}-u_{w}\right)^{0.45}\right] \cdot \tan \varphi^{\prime} \\
\left(\sigma_{n}-u_{a}\right)=\gamma \cdot z \cdot \cos ^{2} \alpha-u_{a} \\
F S=\left(\tau_{f}\right) /\left(\tau_{m}\right)=\left\{\left[\gamma z \cos ^{2} \alpha-u_{a}\right)+\left(\mathrm{u}_{\mathrm{a}}-\mathrm{u}_{\mathrm{w}}\right)^{0.45} \tan \phi^{\prime}\right\} /[\gamma z \cos \alpha \operatorname{sen} \alpha]
\end{gathered}
$$

In these relationships $\alpha$ is the inclination of the ground and failure surfaces with respect to the horizontal and c' and $\varphi$ ' are the two shear strength parameters. Based on available data on soil composition it was assumed $c^{\prime}=0$ and $\varphi^{\prime}=30^{\circ}$. A constant value of unit weight, $\gamma=$ $20 \mathrm{kN} / \mathrm{m}^{3}$, is assumed below and above the water table.

The factor of safety Fs is given by the ratio between the available shear strength $\left(\tau_{f}\right)$ and the applied or mobilized shear stress $\left(\tau_{\mathrm{m}}\right)$; it varies with the depth $\mathrm{z}$ of the slip surface below ground. Pore water pressures along this surface are obtained from the water balance analyses describe previously. Two modes of failure have been examined; deep seated slides with the failure surface (S4) at top of the marly-limestone bedrock (depth of $6 \mathrm{~m}$ ); shallow slides along planar surfaces at depths of $1.0 \mathrm{~m}(\mathrm{~S} 1), 1.5 \mathrm{~m}(\mathrm{~S} 2), 2.0 \mathrm{~m}(\mathrm{~S} 3)$, thus above the groundwater table (Figure 5).
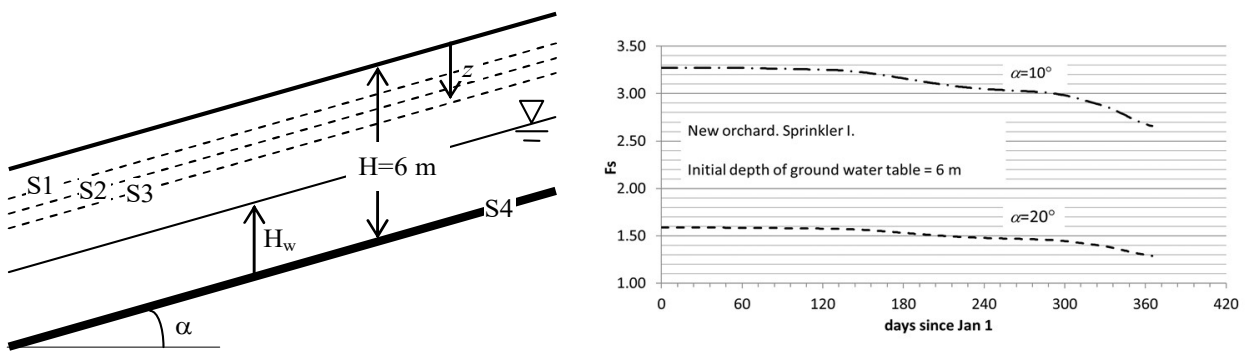

Fig. 5. Slope geometry for stability analyses along various slip surfaces (left); variation of the factor of safety (1 year interval) for sliding along the deep seated (S4) surface (right).

For deep seated slides, the factor of safety is linearly dependant on the height of the groundwater table above the slip surface $\left(\mathrm{H}_{\mathrm{w}}\right)$. Figure 5 shows the variation of the factor of safety during the one year time interval in the case of newly planted trees ( 1 year age) with sprinkler irrigation and initial water table set at a $6 \mathrm{~m}$ depth; two values of slope inclination are presented, $\alpha=10^{\circ}, \alpha=20^{\circ}$. Minimum factor of safety is 1.29 at the end of the year with $\alpha=20^{\circ}$. The slope would fail if $\alpha$ was equal to $25.11^{\circ}[18]$. When the water table is set at a 5 
$\mathrm{m}$ depth the minimum Fs reduces to 1.08 .

The three slip surfaces representing shallow slides $(\mathrm{S} 1, \mathrm{~S} 2, \mathrm{~S} 3)$ remain above the water table throughout the year; along these planes the pore water pressures are negative and the stability conditions are satisfied even for slopes dipping at angles $\alpha$ greater than the friction angle $\left(\varphi^{\prime}=30^{\circ}\right)$. Figure 6 shows the variation of the factor of safety during the one year time interval in the case of grass, newly planted and mature trees ( 1 and 5 years age) with sprinkler irrigation and initial water table set at a $6 \mathrm{~m}$ depth; two values of slope inclination are presented, $\alpha=32^{\circ}, \alpha=35^{\circ}$. When $\alpha=32^{\circ}$ the factor of safety is greater than unity for the three slip surfaces; for the steeper slope, $\alpha=35^{\circ}$, the factor of safety drops below unity for the S2 slip surface for newly planted trees (1 year old).
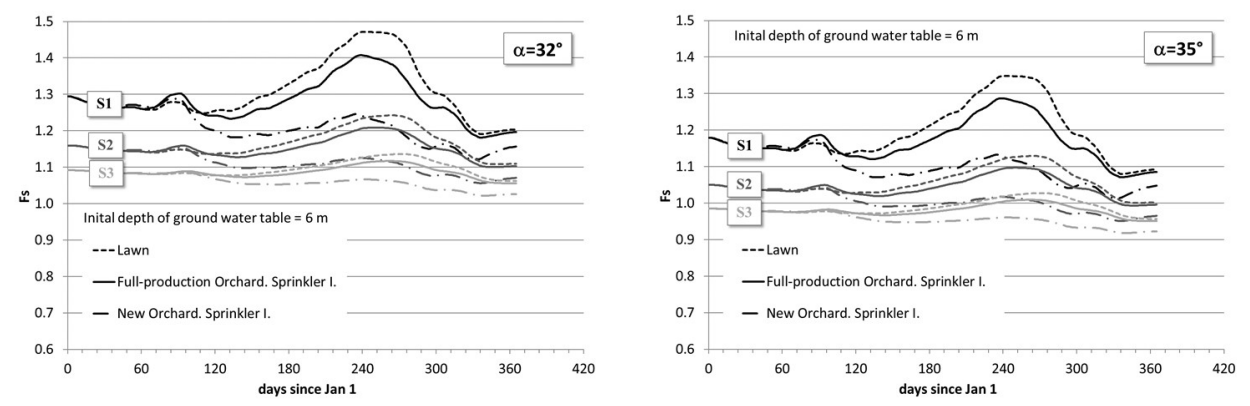

Fig. 6. Variation of the factor of safety (1 year interval) for shallow slip surfaces (S1, S2, S3) dipping $32^{\circ}$ and $35^{\circ}$, for grass, young and mature trees with sprinkler irrigation.

\section{Conclusions}

This paper presents the results of a preliminary study aimed at predicting the variation of the factor of safety of sloping grounds after modifying the agricultural conditions. The kind of modification examined herein is from not irrigated grassland into irrigated high yield apple trees, newly planted ( 1 year old) and fully productive and mature ( 5 years and above).

To investigate the response of the slope, the evolution of the pore water pressures with depth is reconstructed throughout a typical four seasons period; therefore an average one year long time history of rain and temperature at the ground-air interface is considered.

Calculations consider net precipitations and net irrigation, water evaporations from the soil and plant transpiration, infiltration due to irrigation. Evaporations and infiltration, from rain and irrigation, are related to the climate history at ground level and to the suctionsaturation response in the presence of grass and of apple trees, young and mature.

The original grassland is the reference condition, compared to the effects of the apple trees with their water consumptions, increasing with the age, from 1 to 5 years age.

Plant transpiration is calculated using literature relationship $[10,11]$ and considering sprinklers or rain irrigation, requiring abundant volumes of water to account for surface runoff, and drip irrigation, with localized outlets and no runoff losses.

The pore water pressures with time are determined from a water balance through the ground surface, considering the flux in a soil column with unit cross section, and extending to a depth of $6 \mathrm{~m}$, where a relatively impervious bedrock is reached in the study area. The natural groundwater table has been set at depths of $5 \mathrm{~m}$ and $6 \mathrm{~m}$.

The maximum pore water pressure increase is determined from the end of the Summer to the first half of Autumn, and for newly planted apple trees, within their first year. Under such conditions the water table rises and soil suction drops to the lowest values.

Stability analyses consider an infinite slope under seepage; flow lines are parallel to the 
ground and the slip surfaces. Pore water pressures are copied from the previous analyses and applied on a plane perpendicular to the ground surface, the slip surface, the flow lines.

The shear strength of the soil is calculated using the classical Mohr-Coulomb failure criterion with constant $\varphi^{\prime}=30^{\circ}$ and no cohesion for saturated conditions and positive pore pressures. For unsaturated conditions the contribution of suction in terms of shear strength increase is included, taking into account the degree of saturation, the corresponding suction and the suction at the air entry value. The reinforcing effects of tree roots are neglected.

Two failure mechanisms have been analysed, deep seated slides and shallow slides with variable inclinations. Results of the analyses give evidence of the detrimental effects of intensive cultivation and large irrigation compared to plant evapotranspiration, in terms of modified pore water pressures distribution with depth and safety conditions.

\section{References}

1. L. Xu, F. Dai, LG. Tham, X. Tu, Y. Jin, Landslides in the transitional slopes between a loess platform and river terrace, northwest China, Environ. and Eng. Geoscience, 17(3) (2011)

2. L. Xu, FC. Dai, QM. Gong, Irrigation-induced loess flow failure in Heifangtai Platform, North-West China, Environ. Earth Science 66 (2012)

3. H. Li, Y. Jin, Initiation analysis of an irrigation-induced loess landslide, App. Mech. and Materials 170-173 (2012)

4. J. Kozeni, Ueber kapillare Leitung des Wassers im Boden, Wien Akad. Wiss. Vol. 136, (1927)

5. R.P. Chapuis, Permeability tests in rigid-wall permeameters: Determining the degree of saturation, its evolution and influence on test results, Geotech. Testing Jour. 27 (2004)

6. M.T. van Genuchten, A closed-form equation for predicting the hydraulic conductivity of unsaturated soils. Soil Sci. Soc. Am. Jour., Vol. 44 (1980)

7. H. Vereecken, J. Maes, J. Feyen, P. Darius, Estimating the soil moisture retention characteristic from texture, bulk density, and carbon content, Soil Science, Vol. 148 (1989)

8. W.R. Gardner, Some steady-state solutions of the unsaturated moisture flow equation with application to evaporation from a water table, Soil Science 85 (1958)

9. H. Vereecken, J. Diels, J. van Orshoven, J. Feyen, J. Bouma, Functional Evaluation of Pedotransfer Functions for the Estimation of Soil Hydraulic Properties, Soil Science Soc. Am. Jour., Vol. 56 (1992)

10. Bosco G., Simeoni L., Dalpiaz M., 2016. Agricultural effects on air-soil exchange and slope instability. Environmental Geotechnics, Ahead print, doi: http://dx.doi.org/10.1680/jenge.15.00057.

11. J.L. Monteith, Evaporation and environment: the state and movement of water in living organisms, Symp. Soc. Exp. Biol. 19 (1965)

12. P.G. Jarvis, K.G. McNaughton, Stomatal control of transpiration: scaling up from leaf to region, Adv. Ecol. Res. 15 (1986)

13. A.R. Pereira, S. Green, N.A. Villa Nova, Penman-Monteith reference evapotranspiration adapted to estimate irrigated tree transpiration, Agric. water manag. 83 (2006)

14. J.J. Landsberg, D.B.B. Powell, Surface exchange characteristics of leaves subject to mutual interference, Agric. Meteorol. 13 (1973)

15. G.W. Wilson, D.G. Fredlund, S.L. Barbour, The effect of soil suction on evaporative 
fluxes from soil surfaces, Can. Geotech. Jour. 34 (1977)

16. A.W. Bishop, The principle of effective stress, Teknisk Ukeblad, 39 (1959)

17. N. Khalili, M.H. Khabbaz, A unique relationship for $\chi$ for the determination of the shear strength of unsaturated soils, Géotechnique, Vol. 48 (1998)

18. Bosco G., Dalpiaz M., Simeoni L., 2016. Effects of modified irrigation procedures on the stability of cultivated slopes. Atti 12th International Symposium on Landslides, Landslides and Engineered Slopes. Experience, Theory and Practice, Napoli 2016, Vol. 2, pp. 483-48. 